\title{
Criterion and Performance of Elite Bread Wheat Genotypes Pertaining to Physiological Traits under Abiotic Conditions
}

\author{
G. S. Mavi*, Harinderjeet Kaur, Parminder Kumar and V. S. Sohu \\ Department of Plant Breeding and Genetics, \\ Punjab Agricultural University, Ludhiana, India-141004 \\ *Corresponding author
}

\begin{abstract}
A B S T R A C T
Due to increasing temperature drastic reduction in wheat yield was observed. In late sown condition plants face high temperature stress. In the present study the effect of late sown/stressed condition on yield and yield related attributes was investigated in comparison to timely sown/non-stressed condition at Punjab Agricultural University, Ludhiana. The experiment comprised of two sowing dates non-stressed/timely sown and stressed/late sown. Performance of twenty-five genotypes was evaluated under both sowing conditions. Results revealed that significant variation for number of productive tillers, Biomass/net plot, grain weight/net plot, thousand grain weight, grain weight and grain number per spike and yield was observed between non-stressed and stressed condition. The contents were higher in case of non-stressed condition. There was no influence of stressed condition on crop emergence. Genotypes DBW 14, PBW 820 and WH 1239 perform better under timely sown conditions. In late sown condition high temperature at reproductive stage is one of the major factor for yield loss. In stressed condition number of productive tillers decrease by $12.97 \%$, grain weight by $22.32 \%$ and yield by $22.46 \%$. Whereas, genotypes PBW 796 and PBW 821 perform better in stressed condition. Among all the genotypes PBW 821 gives superior results for yield and yield related parameters in stress condition.
\end{abstract}

\section{Keywords}

Heat stress, grain yield, NDVI, chlorophyll, canopy temperature

Article Info

Accepted:

05 June 2020

Available Online:

10 July 2020

\section{Introduction}

Wheat (Triticum aestivum L.) is one of the most significant food crop for burgeoning population of the world. It is staple food in India and grown on an area of $31.19 \mathrm{Mha}$ with production of $95.91 \mathrm{Mt}$ and productivity of 2.4t/ha which contributes around 12 percent of total food grain production (Paswan et al., 2017). In Punjab, it was grown on an area of
34.95 lakh hectares during 2016-17 with production of 176.36 lakh tonnes and average yield of 50.46 quintals per hectare (Anonymous 2019).

In India it is grown in winters as a rabi crop (November to March). It requires cool and moist weather at vegetative stage, and warm and dry weather during reproductive phase. Being a sensitive crop, moisture and 
temperature at sowing time, and temperature at grain filling time are the two most critical factors (Pandey et al., 2015). The crop sown on different sowing dates is exposed to variable climatic conditions which has an impact on its growth and yield. Optimum temperature at anthesis and grain filling ranges between $12-22^{\circ} \mathrm{C}$, whereas temperature $>30^{\circ} \mathrm{C}$ at pre or post-anthesis stage reduces grain filling in wheat.

Rising of mean global temperature to $0.3 \%$ per decade may cause $50 \%$ decline in wheat yields in South Asia by 2050. This is due to the heat stress that causes physiological, biochemical and morphological changes in wheat (Wahid et al., 2007). Sowing of wheat begins as fields get vacated by previous kharif crop. If the earlier crop is harvested late, the wheat sowing is delayed which has severe impact on the mature crop which is exposed to terminal heat stress resulting in drastic reduction of yield. One of the primary factors in timely sown wheat is lengthening of vegetative phase, which is helpful for increasing the plant height along with sugar reservoirs (Kumar and Kumawat 2014).

There is a very close relationship between temperature and plant development, which impacts various physiological changes like photosynthetic and transpiration rate, stomatal conductance, chlorophyll content, canopy temperature etc. Singh et al., (2017) found that under late sown condition, photosynthesis and stomatal conductance was decreased drastically. However, heat tolerant genotypes maintain high photosynthetic rate and stomatal conductance after anthesis under late sown (stressed) conditions.

Decline in NDVI (normalized difference vegetation index)and chlorophyll content depicts the susceptible and tolerant nature of genotypes under timely and late sown condition. So, measurement of both NDVI and chlorophyll will be advantageous in selection of genotypes (Sharma et al., 2015).High value of chlorophyll and NDVI will lead to longer stay green trait during high temperature, that will contribute to longer grain filling period ultimately resulted in high grain yield (Ramya et al., 2015).

Canopy temperature (CT) is affected by number of physiological parameters directly or indirectly and it indicates fitness of a genotype under adverse conditions. Keeping this in view, the study was conducted to evaluate different physiological parameters, chlorophyll content, NDVI and canopy temperature for identifying promising wheat genotypes under late sown condition which can mitigate the effects of temperature stress.

\section{Materials and Methods}

\section{Experimental layout}

Field experiment was conducted during the rabi season of 2018-19 under two environmental conditions at Punjab Agricultural University, Ludhiana, Punjab, INDIA. Which is situated between $30^{\circ} 54^{\prime}$ north latitude and $75^{\circ} 48^{\prime}$ east longitude. The experiment was conducted to assess the functioning of wheat varieties under nonstressed/timely sown (13-Nov-2018) and stressed/late sown (12-Dec-2018) conditions.

Timely sown crop was harvested on 30-Apr2019 and late sown crop was harvested on 5may-2019. Soil of the experimental field was sandy loam. During the season (Nov 2018April 2019) average air temperature recorded was $17.6^{\circ} \mathrm{C}$, relative humidity was $65.9 \%$ and rainfall was $28.8 \mathrm{~mm}$.

Figure 1 depicted the weekly average temperature, humidity and rainfall data. Recommended package of practices were followed for raising of crop. 


\section{Plant material}

The study material consists of 25 genotypes of Triticum aestivum under timely sown (Non-stressed) and late sown (stressed) conditions. Field trial was put in lattice design (5X5), with row length of $3.0 \mathrm{~m}$ and row spacing of $0.23 \mathrm{~m}$.

\section{Growth characteristics}

Different parameters of growth were recorded from germination to end of the vegetative phase for both sowing conditions. Germination percentage was recorded after 12 days of sowing. Days to heading observations were recorded after two months of sowing. Data for days to anthesis was recorded separately from days to heading in both timely sown and late sown conditions. Number of productive tillers were recorded from $3 \mathrm{~m}$ length of each row for all the genotypes. Biomass per net plot was taken as weight of whole plants with spikes and foliage/net plot. At harvest, plants were threshed and grains obtained per plot were weighed to determine grain weight per plot. Thousand grains were weighed separately to find thousand grain weight of each genotype under non-stressed and stressed conditions. To find grain number per spike and grain weight per spike eight to ten mature spikes from each genotype were selected and hand threshed. Grains obtained from these spikes were counted and weighed. Yield (q/ha) was calculated from grain yield per net plot.

\section{Chlorophyll and NDVI}

Chlorophyll and NDVI content was measured at two stages, stage-I (at anthesis) and stage-II (15 DAA; Day after anthesis) under nonstressed and stressed conditions. Chlorophyll content was measured using hand held chlorophyll meter (SPAD-502 Konica Minolta Sensing, INC, Japan).
It measures chlorophyll content by light transmittance (absorption of red light at 650 $\mathrm{nm}$ and infrared light at $940 \mathrm{~nm}$ ).NDVI data was recorded by using handheld Green Seeker (The Trimble Navigation Limited, US) crop sensing system. NDVI measures vegetation by calculating the difference between nearinfrared (which vegetation strongly reflects) and red light (which vegetation absorbs), its value vary from -1 to +1 .

$$
\text { NDVI }=\frac{\text { NIR-Red }}{\text { NIR+Red }}
$$

NIR $=$ Near infrared reflected, Red: Absorbed red light

\section{Canopy temperature (CT)}

Canopy temperature $\left({ }^{\circ} \mathrm{C}\right)$ was determined using infrared thermometer (LT 300 Sixth sense) for both sowing conditions at anthesis and 15 DAA.

\section{Results and Discussion}

The experiment was conducted to screen the genotypes having good physiological characters, yield and yield attributes under non-stressed and stressed conditions. Phenology data like days to heading, days to anthesis and days to maturity was taken during growth of the crop. Wheat genotypes under study did not show any significant difference for average percent germination 89\% under non-stressed and stressed conditions (Fig 2, 4a), whereas difference was recorded in days to heading and anthesis under both sowing conditions (Fig 3). In nonstressed condition average number of days to heading and anthesis were 101 and 107 whereas in stressed condition it was 89 and 95 respectively (Fig $4 \mathrm{~b}$ and 4c).Under stressed condition on an average genotypes take 132 days to mature as compare to non-stressed 
condition, which takes 154 days to mature (Fig 4d). In non-stress condition genotype HD 3293 (132days) and in stress condition genotype RAJ 4529 (125days) takes least number of days to mature (Fig 3).Data presented in Fig 3 and Fig 4e shows that average number of productive tillers $/ \mathrm{m}^{3}$ in non-stressed condition were higher (239 tillers) than stressed condition (208 tillers).

It was found that non-stressed condition brought about 14.7 percent higher number of tillers $/ \mathrm{m}^{3}$ as compare to stressed condition. This might be due to favorable temperature for wheat growth and accumulation of photosynthetic metabolites under timely sown conditions that results in higher yield. Maximum number of productive tillers $/ \mathrm{m}^{3}$ were found in HD-2932, PBW 796 and PBW 821genotypes under non-stressed conditions (Fig 3).

Stress conditions decreased grain weight per net plot, biomass per net plot, 1000 grain weight, grain number and weight/spike, and yield. Sowing at time significantly influence entire attributes of yield and significantly superior than late sowing conditions.

\section{Grain weight/net plot}

Grain weight (g) per net plot for non-stressed and stressed conditions is shown in Fig 5. Average grain weight taken under nonstressed condition (1707g) was $22.3 \%$ higher than the stressed condition (1326g) (Fig8b).

Maximum grain weight per net plot under non-stressed condition is shown by genotypes HD 2932 (2265g), PBW 820 (2164g) and WH 1239 (2176g), whereas under stressed condition it was found in PBW 796 (1626g) (Fig 5). Genotypes NW 7049, RWP-2018-31 and WH 730 give better grain weight/net plot in stressed condition than under non-stressed condition.

\section{Biomass/plot}

Biomass was ranged from $2873 \mathrm{~g}$ to $5050 \mathrm{~g}$ in non-stressed and $2377 \mathrm{~g}$ to $4212 \mathrm{~g}$ in stressed condition. Average biomass/ plot decrease by $16.9 \%$ under stressed condition as compare to non-stressed condition, and the content was $4033 \mathrm{~g}$ in non-stressed and 3349g in stressed condition (Fig 8a). Under non-stressed condition genotypes PBW 820 and WH 1239 recorded the highest biomass $(5055 \mathrm{~g} / \mathrm{plot})$. Whereas genotype PBW 821 accumulate higher biomass under stressed condition.

\section{Grain number and grain weight/spike}

Grain number and grain weight/spike presented in (Fig6). It revealed that in nonstressed condition the average number of grains/spike is higher than stressed condition (Fig8d). Under non-stressed condition there were $6.1 \%$ more number of grains per spike as compare to stressed condition. Genotypes DBW 14, DBW 257 and PBW 781 shows maximum number of grains/spike under nonstressed condition. Under stress condition genotypes like PBW 821, RWP-2018-26, RWP-2018-28 and SBP-MABB2 shows increase in number of grains per spike from that under non-stressed condition (Fig 6). Regarding the average grain weight/spike it was higher in non-stressed condition as compare to stressed condition (Fig8e). Genotypes DBW 14, DBW 257, DBW 71 and PBW 781 shows highest grain weight per spike under non-stressed condition. Whereas, genotypes HD 3293, PBW 821, RWP-201826 and RWP-2018-28 showed small increase in grain weight per spike under stressed condition (Fig 6).

\section{Thousand grain weight}

Under non-stressed condition highest thousand grain weight of $43 \mathrm{~g}$ and $42.5 \mathrm{~g}$ was found in NW 7049 and DBW 71 genotype 
(Fig 7). Average thousand grain was higher in non-stressed conditions as compare to stressed condition (Fig8c). Thousand grain weight in genotypes DBW 273, PBW 821, RWP-2018-30 and RWP-2018-31 was at par under both sowing conditions whereas, under stressed condition three genotypes HD 3293, PBW 820 and RAJ-3765 shows increase in thousand grain weight as compare to wheat genotypes under non-stressed condition (Fig 7).

\section{Grain yield}

Wheat under non-stressed condition had significantly higher yield as compare to stressed condition (Fig 7). Under non-stressed condition average yield was $61.9 \mathrm{q} / \mathrm{ha}$ whereas, under stress condition it was 48.0 $\mathrm{q} /$ ha (Fig.8f). There is $22.4 \%$ decrease in yield ( $\mathrm{q} / \mathrm{ha}$ ) under stress condition from nonstress condition, this decrease was mainly due to elevated temperature during milking and grain filling stage. Highest yield was recorded in HD 2932 (82.1 q/ha) followed by WH 1239 (78.9 q/ha) and PBW 820 (78.4 q/ha) under non-stressed condition (Fig 7). Under stressed condition highest percent decrease in yield of $41.2 \%$ was found in genotype DBW 14 followed by $37 \%$ in RWP2018-27 and 35.6\% in HD 2932 whereas genotype WH 730 under similar condition reported $16.4 \%$ increase in yield(q/ha).

\section{Chlorophyll content}

Observation of average chlorophyll content at anthesis and 15DAA were at par in nonstressed condition. Whereas, under stress condition decrease of $9.4 \%$ was observed (Fig $12 \mathrm{a}, \mathrm{b})$. This decrease may be due to high temperature in stressed condition at anthesis and 15DAA.At anthesis stage highest chlorophyll content was recorded under stressed condition in genotypes PBW 796(44.1), PBW 821(44.4) and RWP-2018-
31(44.3). Whereas in 15DAA highest chlorophyll content was found under nonstressed condition in genotypes RWP-201827(44.2), RWP-2018-28 (43.9), NW 7049(43.4), PBW 781(43.4), and WH 1239 (43.4).

\section{Normalized difference vegetation index (NDVI)}

NDVI values at anthesis and 15DAA under both sowing conditions presented in Fig 10. NDVI value was higher in stressed condition at both the stages (Fig 12c, d). Average value of NDVI was same at anthesis and 15DAA in non-stressed condition. Whereas, in stressed condition $17.0 \%$ decrease in average value of NDVI was observed. At anthesis maximum NDVI value of 0.62 was found in stressed condition in genotypes DBW 14 and WH 730 (Fig 10).

\section{Canopy temperature (CT)}

Canopy temperature under non-stressed and non-stressed condition at anthesis and 15DAA was depicted in Fig $(12 \mathrm{e}, \mathrm{f})$ the. Average canopy temperature was lower under nonstressed condition than stressed condition at anthesis and 15DAA(12e, f). Under nonstressed condition genotype DBW 257 and RWP-2018-27 shows minimum canopy temperature at both the stages.

Temperature affect almost all the stages of wheat involving germination, tillering, booting, anthesis, grain filling and ripening. It influences water and nutrient supply necessary for the growth. Various authors studied the high temperature effect in timely sown and late sown conditions in wheat cultivars (Mahajan et al., 2018, Kumar et al., 2018, Pandey and Tiwari 2019).Different approaches have been used by various researchers to study the effect of elevated temperature on yield in wheat varieties, out of 
which one of the approach is the late sown (stressed) condition. Late sown condition exposes the plants to low temperature stress at germination and high temperature stress at post anthesis stage which decrease the grain filling period that will consequently reduce yield (Pandey et al., 2014). Temperature below or above the normal level leads to decrease in plant function and productivity (Hossain et al., 2012). Temperature below 10$12^{\circ} \mathrm{C}$ results in poor or uneven germination (Timmermans et al., 2007, Farooq et al., 2008). In our study no significant difference was observed for percent germination between timely sown and late sown condition. This may be due to the average temperature of $>19^{\circ} \mathrm{C}$ in timely sown and $>13^{\circ} \mathrm{C}$ in late sown condition, which is favorable at time of germination. Average germination percentage was $89 \%$ in both sowing conditions (Fig 2, Fig 4a). Kumari et al., (2018) reported almost equal germination percentage of $80-85 \%$ in both timely sown and late sown conditions.

Number of days to heading or ear emergence from its surrounding leaves is exclusively dependent on the environmental conditions and genetic makeup of the plant. Alteration in temperature will lead to change in number of days to ear emergence. In non-stressed and stressed condition significant difference in number of days to heading was observed i.e. 101 days in non-stressed and 89 days in stressed condition. Under stressed condition genotype DBW 14 takes minimum i.e. 81 days to heading followed by Raj 4529 and SBP-MABB1 which takes 84 days to heading (Fig2).In late sown condition heading was faster than timely sown condition, due to elevated temperature crop completes its life cycle faster than sown under non-stressed conditions. It is also confirmed by earlier studies (Nahar et al., 2010, Hakim et al., 2012). Early heading is more advantageous because more green leaves will be there at the time of anthesis (Hossain et al., 2015).
Average number of days to anthesis was found to be less in stressed condition as compared to non-stressed condition that results in $22.4 \%$ reduction in yield. Ferrie et al., 1998 reported $31^{\circ} \mathrm{C}$ temperature over 8 days at the time of anthesis will lead to $50 \%$ reduction in yield. Under late sown condition crop takes lesser number of days to mature due to high temperature at time of maturity. Under stressed condition on an average plants take 132 days to attain maturity and in nonstressed plants it takes 154 days to mature (Fig3). Many authors observed reduction in number of days to maturity under late sown conditions (Araus et al., 2007, Shahzad et al., 2007, Rahman et al., 2009, Nahar et al., 2010). Ubaidullah et al., (2007) and AlKaraki et al., (2012) reported that under late sown condition plant will suffer high temperature stress that will lead to early heading and forced maturity, shortening of life cycle by plant will take place to overcome high temperature stress. Whereas lengthening of vegetative phase has been found in timely sown condition, which utilize enough time for enhancing their sugar reserve (Kumar and Kumawat 2014).

Number of productive tillers and grain weight per plant are the parameters for selection criteria to improve the grain yield. In late sown condition on an average 208 productive tillers were observed, whereas in non-stressed condition number of productive tillers was 239 in our study (Fig 4e). In timely sown condition number of productive tillers are more due to good germination conditions, extended vegetative phase and good stand establishment (Patil et al., 2001, Singh and Pal 2003). Whereas in case of late sown condition factors responsible for reduction in number of productive tillers are high air and soil temperature, low humidity and soil moisture, (Tahir et al., 2009, Alam et al., 2013). Farooq et al., (2008) observed that low temperature at time of germination in late 
sown condition will lead to poor emergence that will result in fewer number of productive tillers. Biomass per net plot was observed to decrease by $16.7 \%$ in late sown condition as compare to non-stressed condition due to high temperature stress. Pandey and Tiwari (2019) reported $19.12 \%$ reduction in biomass in late sown condition. Analogous results were reported by Tahir and Nakata (2005) they found 20 to $44 \%$ reduction in biomass under late sown condition. High temperature at anthesis and later stages leads to reduction in biomass, grain yield, number of grains per spike, thousand grain weight etc. (Kumari et al., 2013). Grain yield of wheat was influenced significantly due to extended sowing time (Shirpurkar et al., 2008, Mukherjee 2012).

Timely sown condition is superior in grain weight per net plot, grain number and weight per spike, thousand grain weight, biomass production and yield. This may be attributed to better partitioning of photosynthetic metabolites and more time (due to long vegetative phase) for accumulation of more dry matter for high grain yield (Guilioni et al., 2003, Shahzad et al., 2002). Whereas in late sown condition high temperature stress followed by drought at reproductive phase have detrimental effects on anthesis, milking and dough stages. It will lead to decline in number of grains/spike, thousand grain weight and ultimately yield(Pardeshi et al., 2009, Muduli et al., 2010, Jat et al., 2013, Bannayan et al., 2013). Hays et al., (2007) studied that ovule abortion linked to ethylene levels induce programmed cell death and pollen sterility due to high temperature stress at anthesis stage in late sown condition are the reasons for reduction in grain yield, grain number per spike and total yield. Al- Karaki et al., 2007, Prasad et al., 2008 also reported that reproductive phase is the most sensitive period during heat stress, heat stress will lead to ovule abortion, pollen sterility and grain set. Due to high temperature at milking and grain filling stage there will be shrivelling of grain that will lead to reduction in grain weight per plot, number of grains per spike, 1000 grain weight (Kabir et al., 2009, Kumar et al., 2013).

In timely sown condition chlorophyll content at anthesis was at par with chlorophyll content 15DAA. Whereas in late sown condition chlorophyll content decrease from 39.9 to 36.8 from anthesis to 15DAA stage. This may be due to elevated temperature in late sown condition at time of anthesis that will lead to disruption of chloroplast and reduction of chlorophyll will takes place (Brestic et al., 2016, Sunita et al., 2018). Reduction in chlorophyll is associated with reduction in accumulation of photosynthetic metabolites that results in poor grain filling and yield loss (Shanmugam et al., 2013, Ram et al., 2017). Loss of chlorophyll is also associated with membrane damage and leaf senescence (Ristic et al., 2007). In wheat stay green character is associated with ability of a plant to retain chlorophyll even at stressful conditions like heat stress. It will contribute longer grain filling period that will ultimately enhance yield even under high temperature stress (Sangwan et al., 2018). NDVI is a measure of crop biomass production, senescence rate and yield performane. NDVI is associated with chlorophyll content, leaf nitrogen content and photosynthetic efficiency of plant (Tattaris et al., 2016). No difference was observed in NDVI value at anthesis and 15DAA in timely sown condition, whereas reduction in NDVI value (0.53 to 0.44$)$ was observed from anthesis to 15DAA in late sown condition. This may be due to high temperature stress at anthesis and 15DAA stage in late sown condition.

High temperature lead to chlorophyll damage and reduction of NDVI takes place because there is a positive correlation between 
chlorophyll content and NDVI (Sangwan et al., 2018).

High value of chlorophyll content and its association with NDVI resulted in cooler canopies that induces heat tolerance in plants (Ramya et al., 2015, Munjal and Dhanda 2016). Average canopy temperature was lower at both stages (anthesis and 15DAA) in non-stressed condition as compare to stressed condition. Which depicts healthiness of plants to undergo transpiration and to reduce canopy temperature to mitigate heat stress in nonstressed condition. Results are in accordance with Basu et al., (2014) and Kumari et al., (2018), which showed that canopy temperature of late sown crop was higher than timely sown crop.

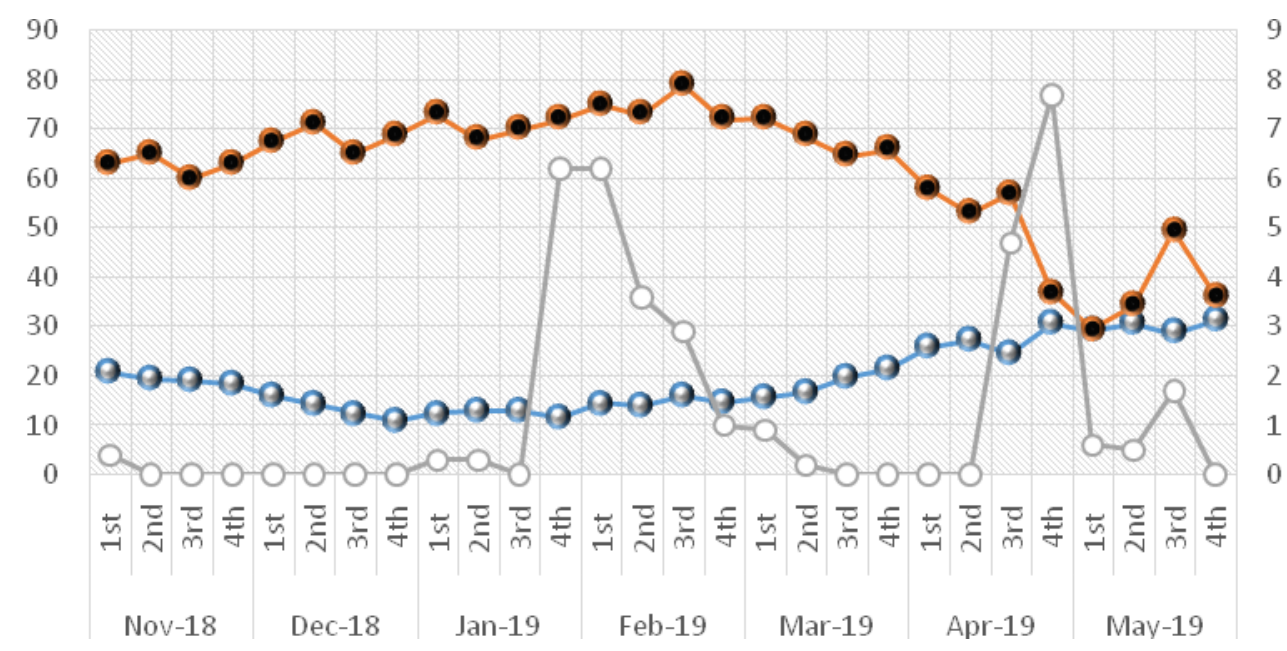

Fig.1 Weekly average temperature, humidity and rainfall during the crop season

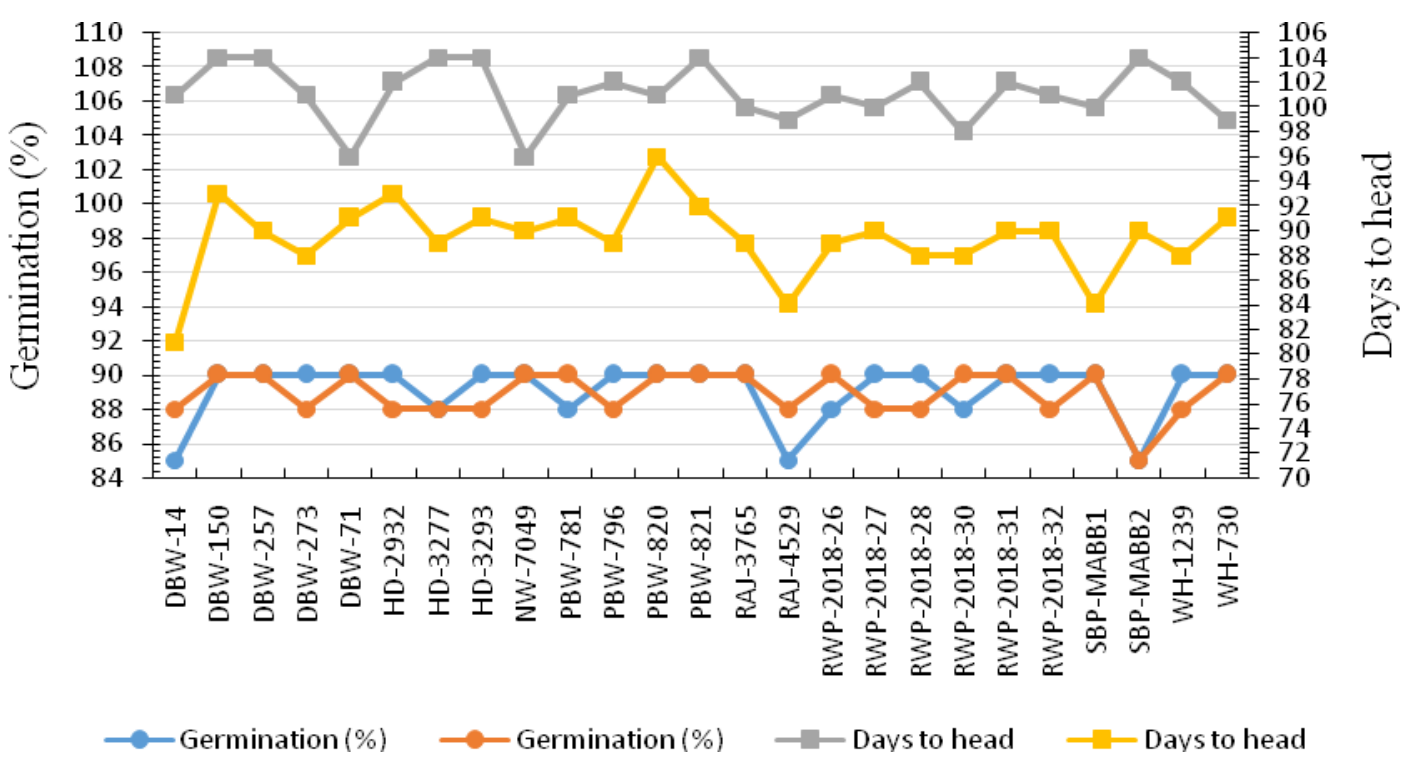

Fig.2 Observations of germination percentage and days to head under non-stress and stress conditions 


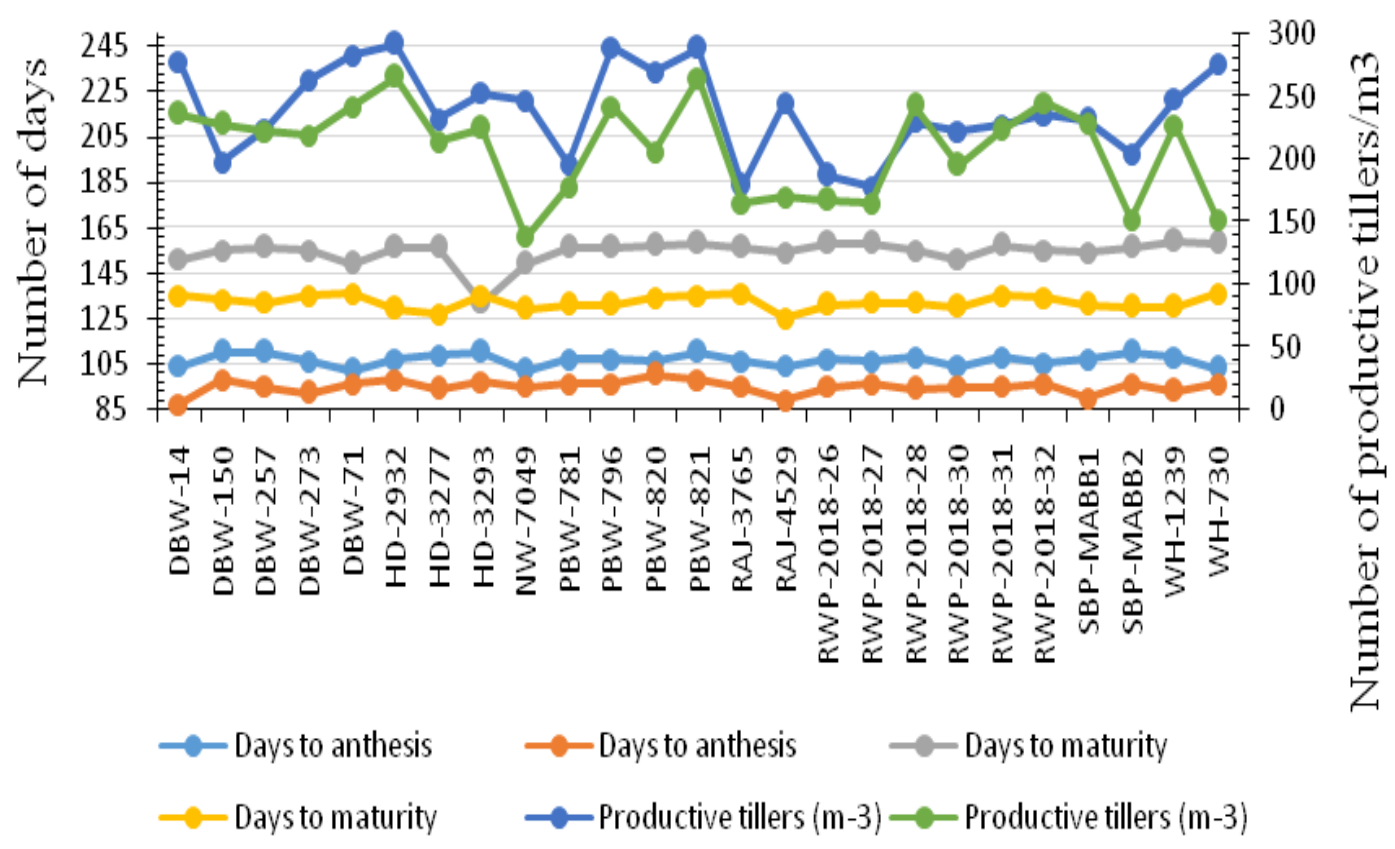

Fig.3 Observations of days to anthesis, days to maturity and number of productive tillers under non-stress and stress conditions

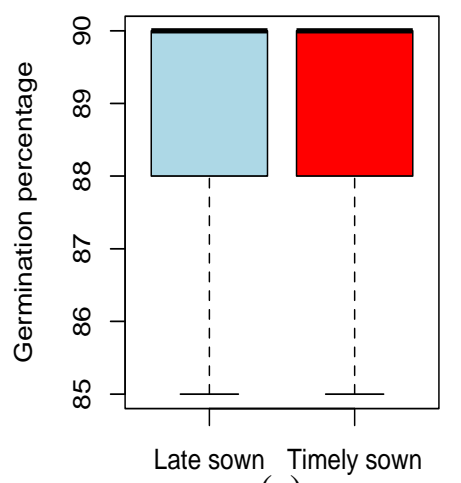

(a)

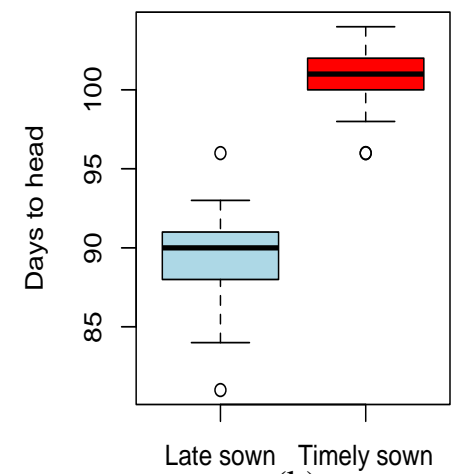

(b)

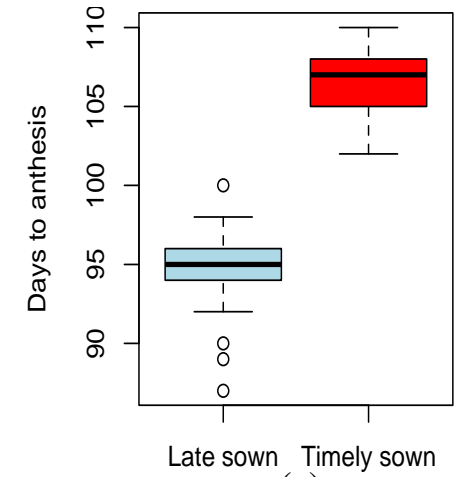

(c)

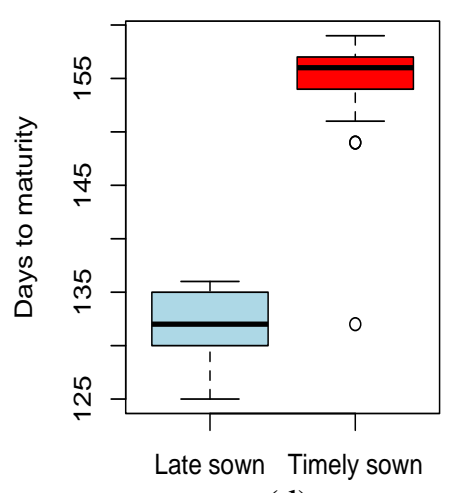

(d)

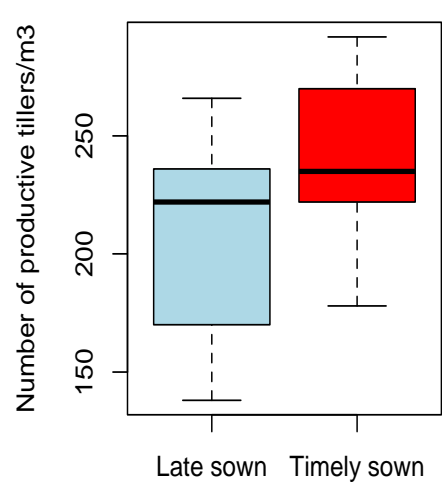

(e)

Fig.4 Box plot showing average germination percentage, days to head, days to maturity and number of productive tillers under non-stress and stress conditions 


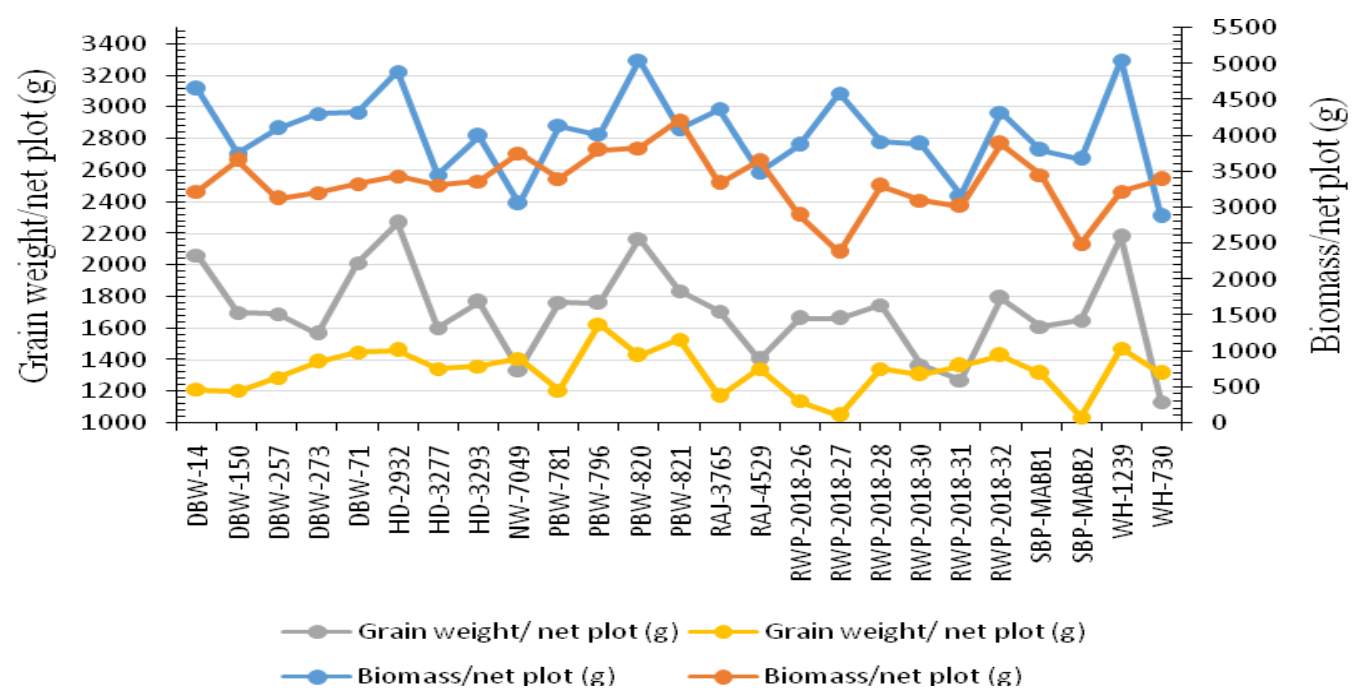

Fig.5 Observations of biomass/net plot and grain weight/net plot non-stress and stress conditions

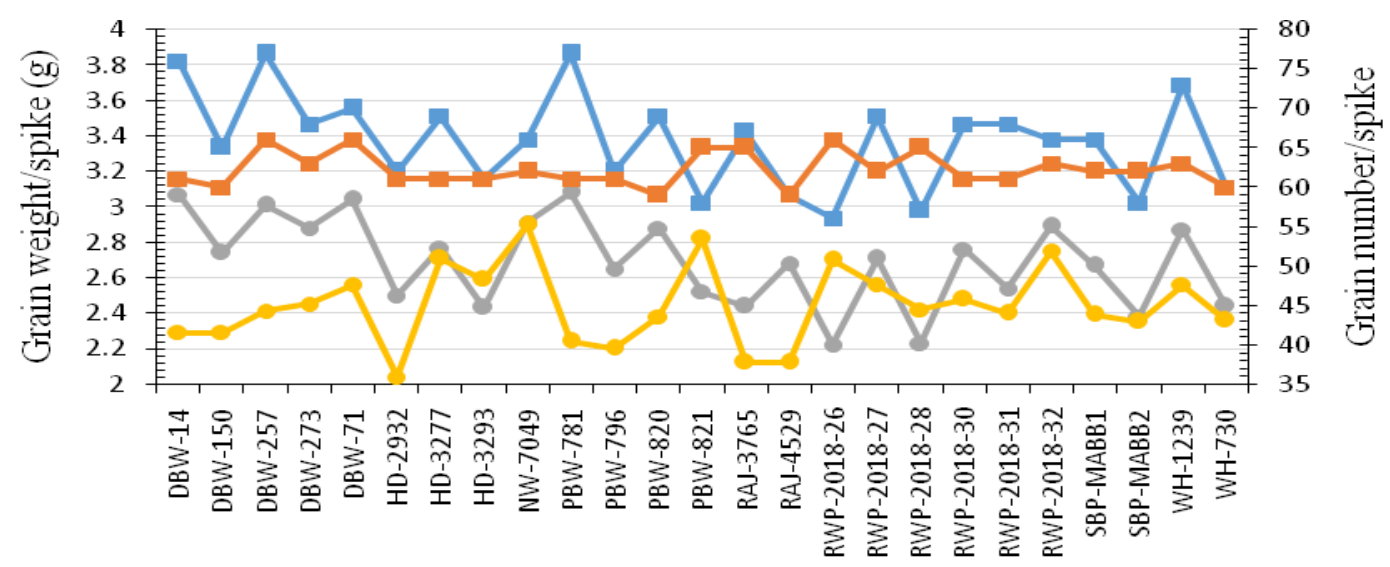

$\longrightarrow \mathrm{GW} / \mathrm{Sp}(g) \longrightarrow \mathrm{GW} / \mathrm{Sp}(g) \longrightarrow \mathrm{GN} / \mathrm{Sp} \longrightarrow \mathrm{GN} / \mathrm{Sp}$

Fig.6 Observations of grain weight/spike and grain number/spike under non-stress and stress conditions

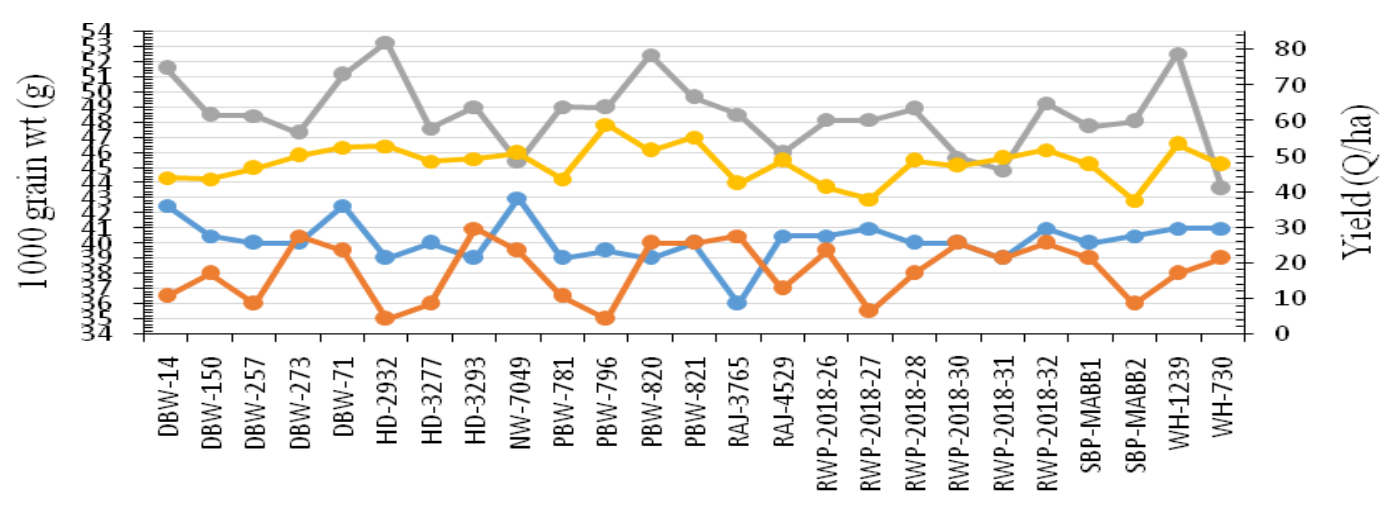

$\longrightarrow 1000$ grain weight $(g) \longrightarrow 1000$ grain weight $(g) \longrightarrow$ Yield $(\mathrm{g} / \mathrm{ha}) \longrightarrow$ Yield $(\mathrm{Q} / \mathrm{ha})$

Fig.7 Observations of thousand grain weight and yield $(\mathrm{Q} / \mathrm{ha})$ non stress and stress conditions 

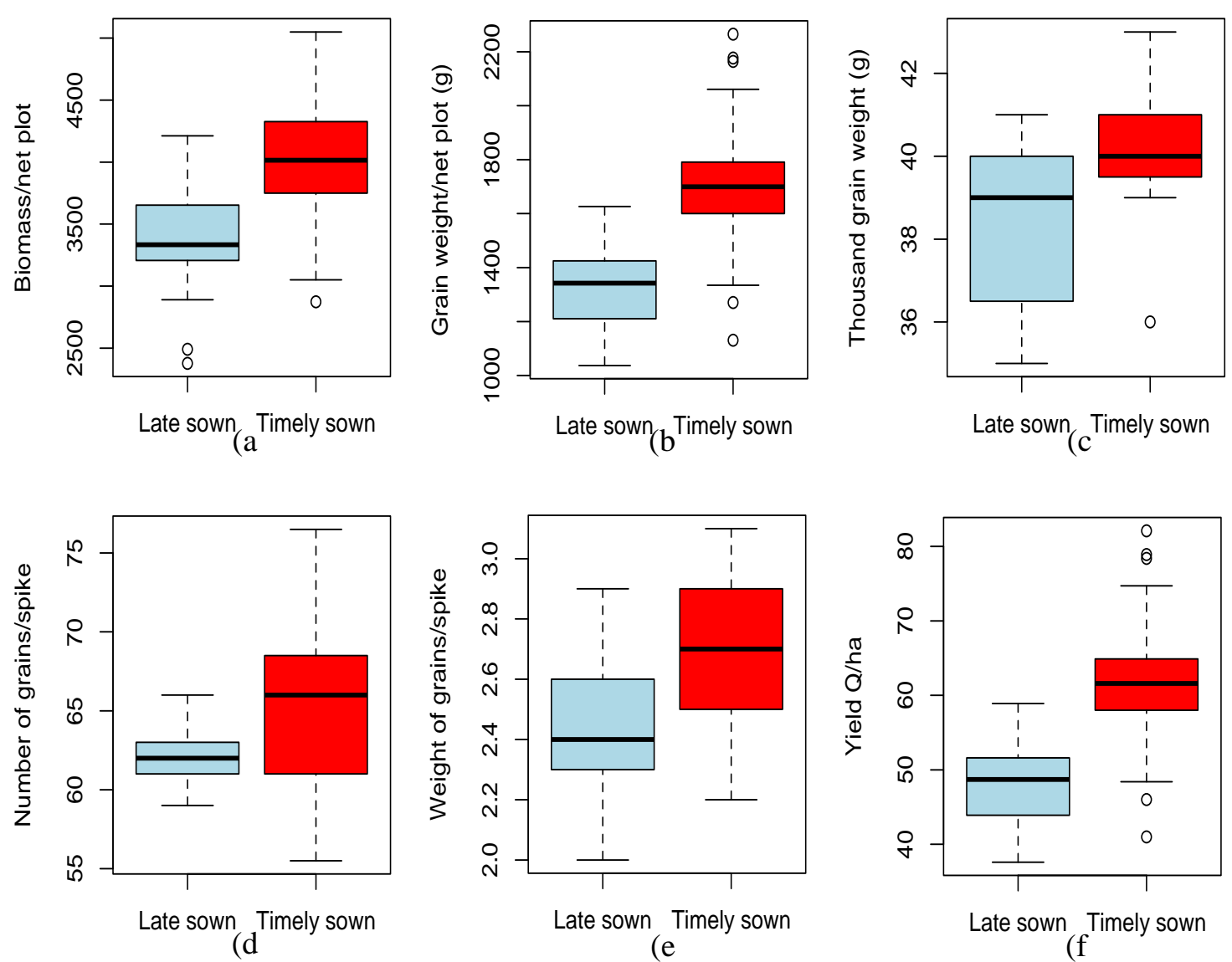

Fig.8 Box plot showing average biomas/net plot, grain weight/net plot, thousand grain weight, grain number/spike, grain weight/spike and yield non-stress and stress conditions

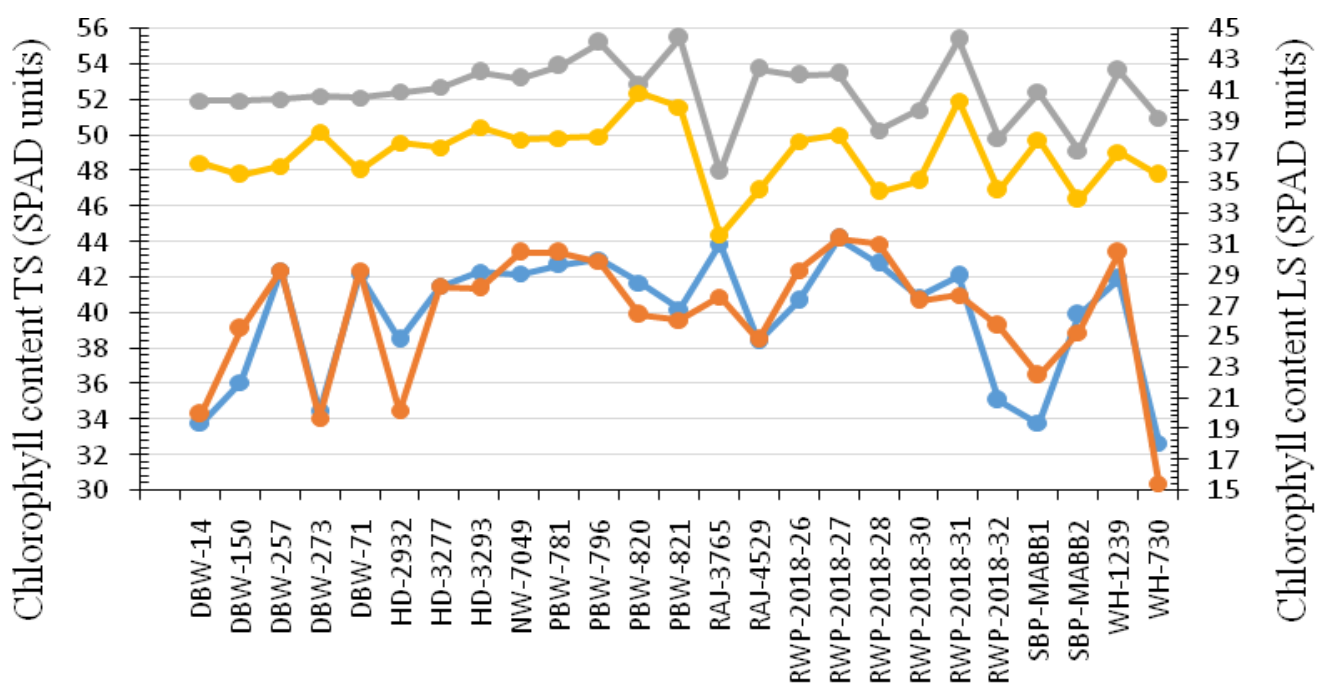$$
\longrightarrow \text { TS }- \text { TS }- \text { IS }- \text { IS }
$$

Fig.9 Observations of chlorophyll content at anthesis and 15 DAA non-stress and stress conditions 


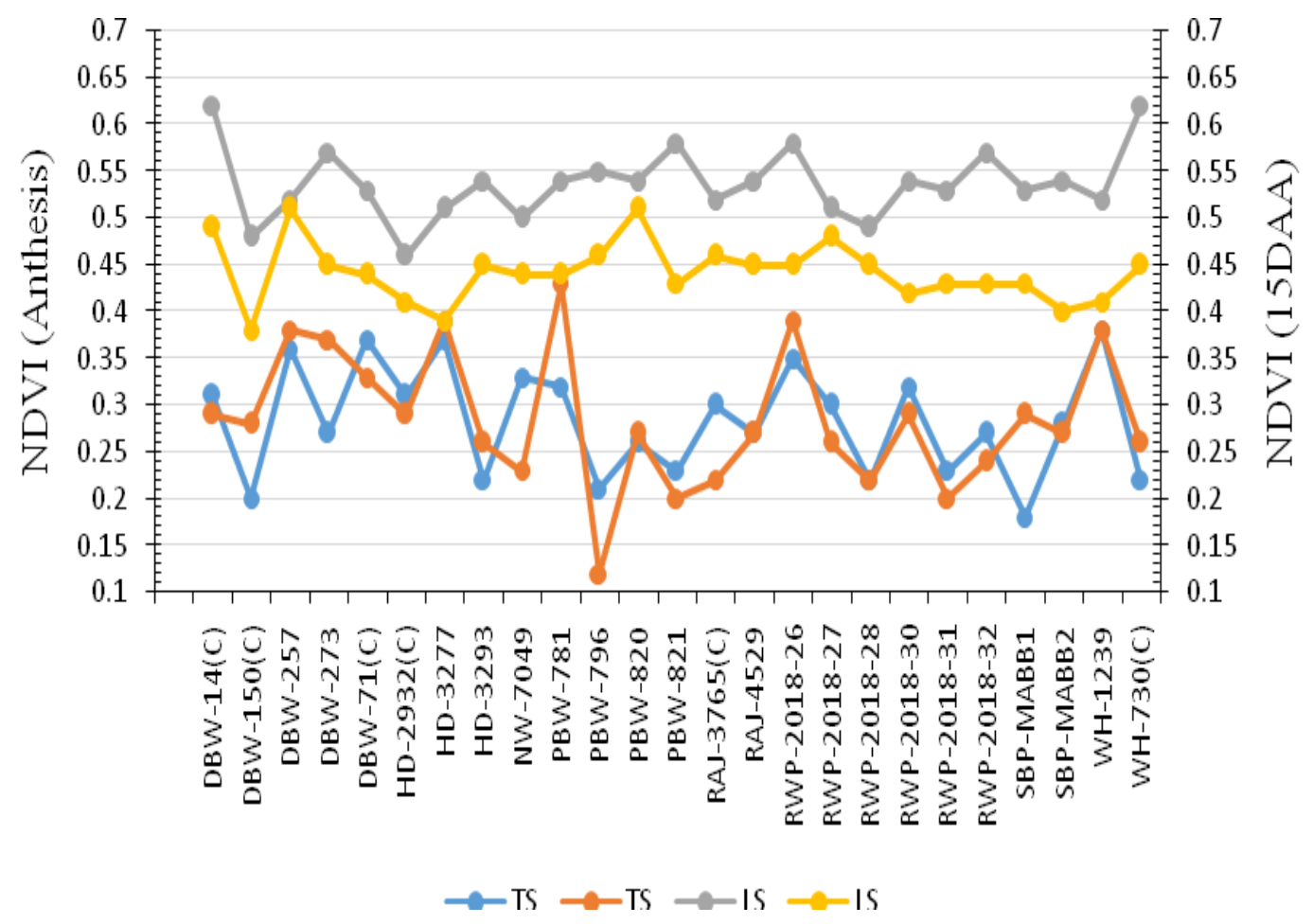

Fig.10 Observations of NDVI at anthesis and 15 DAA under non-stress and stress conditions

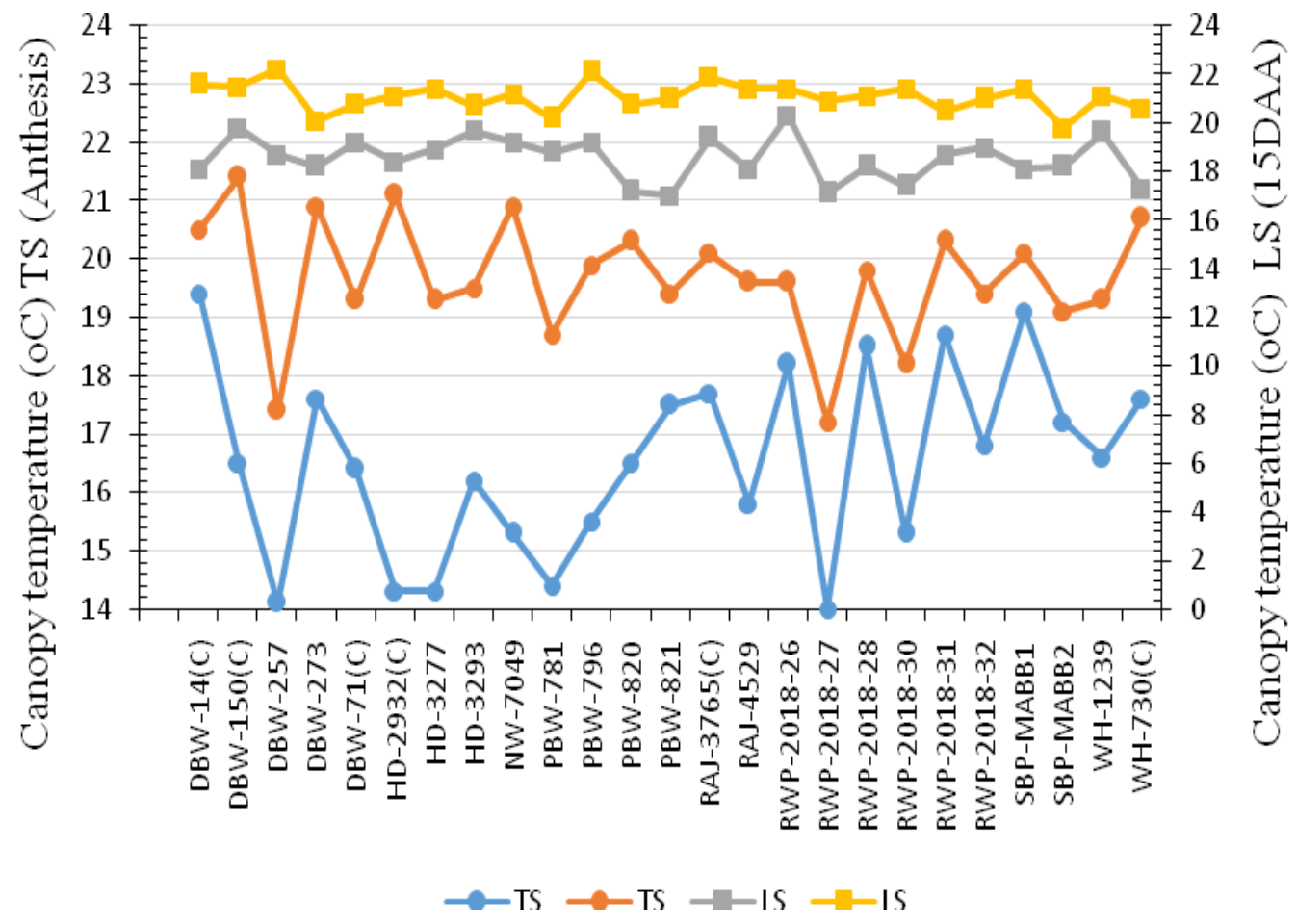

Fig.11 Observations of canopy temperature (CT) at anthesis and 15 DAA under non-stress and stress conditions 

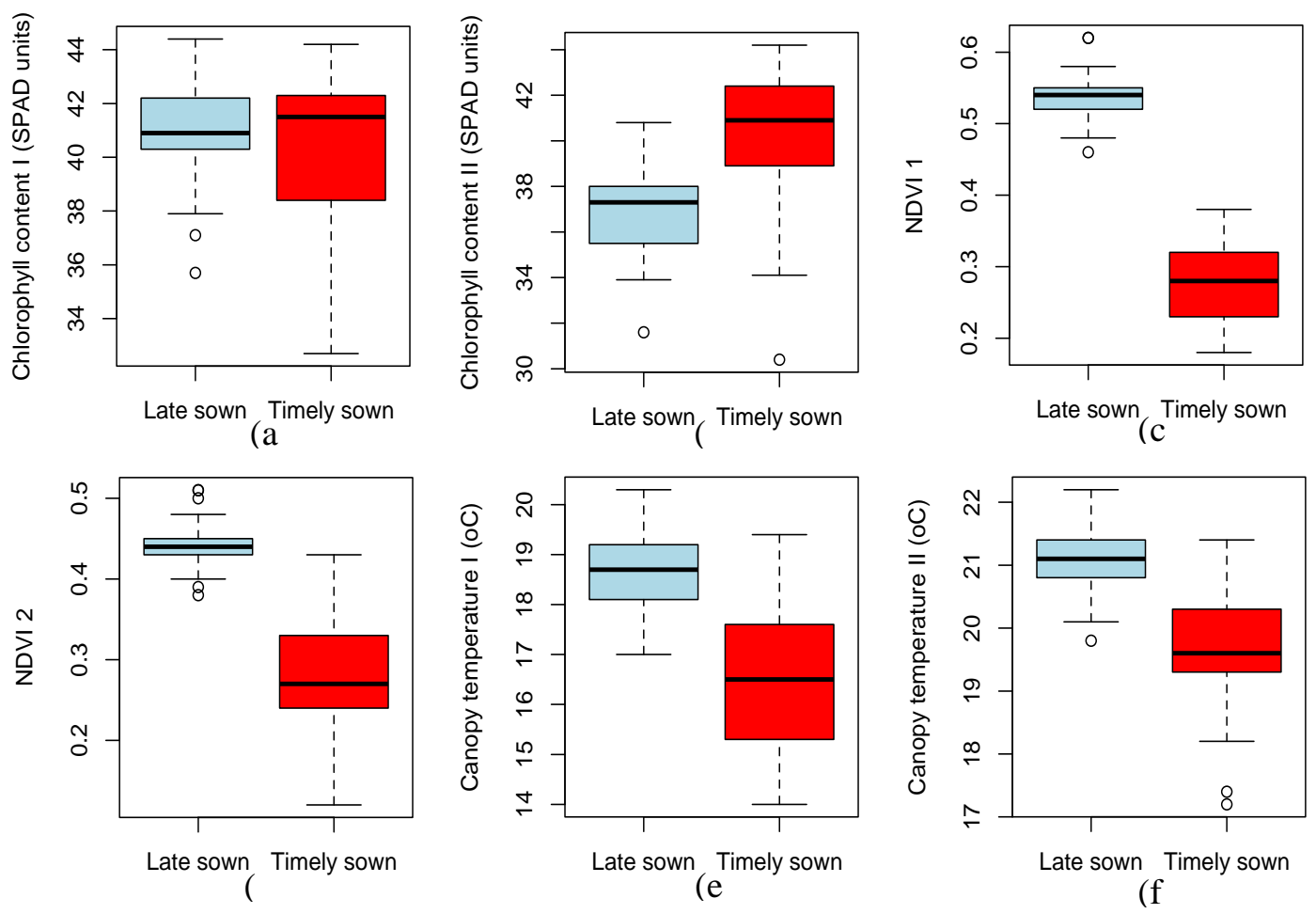

Fig.12 Box plot showing average chlorophyll content, canopy temperature and NDVI value under non-stress and stress conditions at anthesis (I) and 15DAA (II)

From the present study, it can be concluded that genotypes DBW 14, PBW 820 and $\mathrm{WH}$ 1239 have high number of productive tillers, Biomass/net plot, grain weight/net plot, thousand grain weight, grain number and weight/spike and yield under timely sown condition. Two genotypes DBW 71 and HD 2932 perform better under both conditions but the content of various yield and yield related parameters was lower under stress condition as compared to non-stressed condition, but these genotypes perform better than other genotypes under study in stress condition. Two genotypes PBW 796 and PBW 821 were found to perform better in stress condition. From these, PBW 821 perform better at developmental stages (germination percentage, days to heading, days to anthesis, days to maturity) under stressed and nonstressed conditions. Whereas, under late sown condition when temperature is high at reproductive stage, PBW 821 shows higher biomass production, grain weight/net plot, grain number/weight per spike, 1000 grain weight, yield (q/ha), chlorophyll and NDVI at anthesis and 15 DAA, and lower canopy temperature at anthesis. Hence, this genotype may be used in wheat breeding programme for development of heat tolerant varieties.

\section{Acknowledgement}

Thanks to ICAR-IIWBR, Karnal for given that material for the studies. We are also thankful to our institute for providing facilities for conduct of trial.

\section{References}

Alam, M.N., Akhter, M.M., Hossain, M.M. \& Alam, S.M.M. (2013) Phenological changes of different wheat genotypes (Triticum aestivum L.) in high temperature imposed by late seeding. J Biodi Environ Sci3: 8393.

Al-Karaki, G.N. (2012) Phenological development-yield relationships in durum 
wheat cultivars under terminal high temperature stress in semiarid conditions. International Scholarly Research Network, (ISRN Agronomy).

Anonymous (2019) Package of Practices for Rabi Crops of Punjab. Pp 1. Punjab Agricultural University, Ludhiana.

Araus, J., Ferrio, J., Buxo, R. \& Voltas, J. (2007) The historical perspective of dry land agriculture: lessons learned from 10000 years of wheat cultivation. $J$ Exp Bot58: 131-45.

Bannayan, M., Eyshi Rezaei, E. \& Hoogenboom, G. (2013) Determining optimum sowing dates for rainfed wheat using the precipitation uncertainty model and adjusted crop evapotranspiration. Agric Water Manag126: 56-63.

Basu, S., Parya, M., Dutta, S.K., Maji, S., Jena, S., Nath, R. \& Chakraborty, P.K. (2014) Effect of canopy temperature and stress degree day index on dry matter accumulation and grain yield of wheat (Triticum aestivum $\mathrm{L}$.) sown at different dates in the IndoGangetic plains of eastern India. Indian $J$ Agric Res48:167-76.

Brestic, M., Ziveak, M., Kunderlikova, K. \& Allakhverdieve, S.I. (2016) High temperature specially affects the photoprotective responses of chlorophyll-b deficient wheat mutant lines. Photosynth Res130: 251-66.

Farooq, M., Basra, S.M.A, Rehman, H. \& Saleem, B.A. (2008) Seed priming enhancement the performance of late sown wheat by improving chilling tolerance. J Agron Crop Sci194: 55-60.

Guilioni, L., Wery, J. \& Lecoeur, J. (2003) High temperature and water deficit may reduce seed number in field pea purely by decreasing plant growth rate. Funct Plant Biol30: 1151-64.

Hakim, M.A., Hossain, A., Teixeira da Silva, J.A., Zvolinsky, V.P. \& Khan, M.M. (2012) Yield, protein and starch content of 20 wheat (Triticum aestivum L.) genotypes exposed to high temperature under late sowing conditions. J Sci Res4: 477-89.

Hays, D.B., Do, J.H., Mason, R.E., Morgan, G. \& Finlayson, S.A. (2007) Heat stress induced ethylene production in developing wheat grains induces kernel abortion and increased maturation in a susceptible cultivar. Plant Sci172:1113-23.

Hossain, A., Teixeira da Silva, J.A., Lozovs-kaya, M.V. \& Zvolinsky, V.P. (2012) The Effect of high temperature stress on the phenology, growth and yield of five wheat (Triticum aestivum L.) genotypes. The Asian and Aust J Plant Sci Biotech6: 14-13.

Hossain, M.I., Hakim, M.A., Mondal, M.R.I., Gathala, M. \& Barma, N.C.D. (2015) Phenological variation and its relation with yield in several wheat varieties under normal and late sowing heat stress condition in Bangladesh. J Dyn Agric Res2: $1-11$.

Jat, L.K., Singh, S.K., Latare, A.M., Singh, R.S. \& Patel, C.B. (2013) Effect of dates of sowing and fertilizer on growth and yield of wheat (Triticum aestivum) in an Inceptisol of Varanasi. Indian J Agron58: 611-14.

Kabir, M.R., Hossain, A.H., Rahman, M.M., Hakim, M.A. \& Sarker, M.A.Z. (2009) Stability analysis of wheat for grain yield affected by different environment. Bangladesh Res Pub J3: 833-40.

Kumar, A., Swati, Kumar, A., Adhikari, S. \& Prasad, B. (2018) Genetic dissection of wheat genotypes using morpho physiological traits of terminal heat tolerance. Int J Curr Microbiol App Sci.7: 367-72.

Kumar, R. \& Kumawat, N. (2014) Effect of sowing dates, seed rates and integrated nutrition on productivity, pro tability and nutrient uptake of summer mungbean in Eastern Himalaya. Arch Agron Soil Sci 60: 1207-27.

Kumar, S., Alam, P. \& Ali, N. (2013) Response of wheat (Triticum aestivum L.) varieties to sowing dates. J Res25: 56-59.

Kumari, A., Srivastava, M. \& Pandey, H.P. (2018) response of heat tolerance genotypes/varieties on growth of wheat (Triticum aestivum L.) crop under timely and late sown condition. J Pharmacognosy Phytochem7: 768-71.

Kumari, M., Pudake, R.N., Singh, V.P. \& Joshi, A.K. (2013) Association of staygreen trait with canopy temperature depression and yield traits under terminal heat stress in 
wheat (Triticum aestivum L.). Euphytica190: 87-97.

Mahajan, A.Y., Mohite, A.B., Jadhav, Y.R. \& Patil, J.B. (2018) Effect of varieties (Triticum aestivum L.) under extended sowing times on yield, protein content, nutrient uptake and soil properties of wheat. Int J Chem Studies 6: 55-58.

Muduli, K.C., Kar, A.K., Sahu, K.C., Mishra, B.K., Swain, S.K. \& Nayak, R.N. (2010) Influence of sowing dates of seed crops on seed yield and quality parameters in wheat cv. Sonalika. Environ Ecol28: 284-87.

Mukherjee, D. (2012) Effect of different sowing dates on growth and yield of wheat (Triticum aestivum) cultivars under mid hill situation of West Bengal. Indian $J$ Agron57: 152-16.

Munjal, R. \& Dhanda, S.S. (2016) Assessment of drought resistance in Indian wheat cultivars for morpho- physiological traits. Ekin $J$ Crop Breed Genet2: 74-81.

Nahar, K., Ahamed, K.U. \& Fujita, M. (2010) Phenological variation and its relation with yield in several wheat (Triticum aestivum L.) cultivars under normal and late sown mediated heat stress condition. Not Sci Biol2: 51-56.

Pandey, G.C. \& Tiwari, R. (2019) Characterization of terminal heat tolerance in bread wheat (Triticum aestivum L.) using differences in agronomic traits as potential selection criteria. Vegetos32: 200-08.

Pandey, G.C., Mamrutha, H.M., Tiwari, R., Sareen, S., Bhatia, S., Tiwari, V. \& Sharma, I. (2015) Physiological traits associated with heat tolerance in bread wheat (Triticum aestivum L.). Physiol Mol Biol Plants21: 93-99.

Pandey, G.C., Sareen, S., Siwach, P. \& Tiwari, R. (2014) Molecular characterization of heat tolerance in bread wheat (Triticum aestivum L.) using differences in thousand grain weights (dTGW) as a potential indirect selection criterion. Cereal Res Commun 42: 38-46.

Pardeshi, H.P., Jadav, K.V. \& Bagul, R.S. (2009) Yield quality and yield potential of wheat (Triticum aestivum L.) cv. GW 273 as influenced by sowing dates and fertility level. Intl J Agril Sci5: 67-70.
Paswan, A.K., Mandal, D., Kumar, J. \& Kumar, R. (2017) Influence of weed management practices on productivity of wheat (Triticum aestivum L.) under middle Indo-Gangetic Plains of Eastern India. Int.J.Cur.Microbiol.Appl.Sci.6: 2486-91.

Patil, K.S., Durga, D.V., Phadnawis, B.N., Shivankar, R.S. \& Rathod, T.H. (2001) Effect of sowing dates on biomass production of wheat cultivars. Ann Plant Physiol14: 115-19.

Rahman, M.M., Hossain, A., Hakim, M.A., Kabir, M.R. \& Shaha, M.M.R. (2009) Performance of wheat genotypes under optimum and late sowing condition. Int $J$ Sustain Crop Prod4: 34-39.

Ram, K., Munjal, R., Sunita, \& Kumar, N. (2017) Evaluation of chlorophyll content index and normalized difference vegetation index as indicators for combine effects of drought and high temperature in bread. Int J Curr Microbiol Appl Sci6: 528-34.

Ramya, P., Jain, N., Singh, G.P., Singh, P.K. \& Prabhu, K.V. (2015) Population structure, molecular and physiological characterisation of elite wheat varieties used as parents in drought and heat stress breeding in India. Indian $\mathrm{J}$ Genet $\mathrm{Pl}$ Breed75: 250-52.

Ristic, Z., Bukovnik, U. \& Prasad, P.V.V. (2007) Correlation between heat stability of thylakoid membranes and loss of chlorophyll in winter wheat under heat stress. Crop Sci47: 2067-73.

Sangwan, S., Ram, K., Rani, P. \& Munjal, R. (2018) Effect of terminal high temperature on chlorophyll content and normalized difference vegetation index in recombinant inbred lines of bread wheat. Int.J.Cur.Microbiol.Appl.Sci. 7: 1174-83.

Sangwan, S., Ram, K., Rani, P. \& Munjal, R. (2018) effect of terminal high temperature on chlorophyll content and normalized difference vegetation index in recombinant inbred lines of bread wheat. Int.J.Cur.Microbiol.Appl.Sci. 7: 1174-83.

Shahzad, K., Bakht, J., Shah, W.A., Shafi, M. \& Jabeen, N. (2002) Yield and yield components of various wheat cultivars as affected by different sowing dates. Asian $J$ Plant Sci1: 522-25. 
Shahzad, M.A., Sahi, S.T., Khan, M.M. \& Ahmad, M. (2007) Effect of sowing dates and seed treatment on grain yield and quality of wheat. Pak J Agril Sci44: 581-83.

Shanmugam, S., Kjaer, K.H., Ottosen, C.O., Rosenqvist, E., Kumari, S. \& Wollenweber, B. (2013) The alleviating effect of elevated $\mathrm{CO} 2$ on heat stress susceptibility of two wheat (Triticum aestivum L.) cultivars. J Agron Crop Sci199: 340-50.

Sharma, D., Mamrutha, H.M., Gupta, V.K., Tiwari, R. \& Singh, R. (2015) Association of SSCP variants of HSP genes with physiological and yield traits under heat stress in wheat. Res Crops 16: 139-46.

Shirpurkar, G.N., Wagh, M.P. \& Patil, D.T. (2008) Comparative performance of wheat genotypes under different sowing dates. Agricultural Science Digest28: 231-32.

Singh, A.K., Singh, A.K., Kumar, R., Prakash, V., Sundaram, P.K. \& Yadav, S.K. (2017) Indian cereals saga: Standpoint and way forward. Journal of Agri Search4: 1-9.

Singh, S. \& Pal, M. (2003) Growth, yield and phenological response of wheat cultivars to delayed sowing. Indian Journal of Plant Physiology8: 277-86.

Tahir, I.S.A. \& Nakata, N. (2005) Remobilization of nitrogen and carbohydrate from stems of bread wheat in response to heat stress during grain filling. $J$ Agron Crop Sci191:106-15.

Tahir, M., Ali, A., Nadeem, A.N., Hussain, A. \& Khalid, F. (2009) Effect of different sowing dates on growth and yield of wheat (Triticum aestivum L.) varieties in District Jhang, Pakistan. Pak J Life Soc Sci7: 66-69.

Tattaris, M., Reynolds, M.P. \& Chapman, S.C. (2016) A direct comparison of remote sensing approaches for high-throughput phenotyping in plant breeding. Front Plant Sci7: 1131 .

Timmermans, B.G.H., Vos, J., Nieuwburg, J.V., Stomph, T.J., Putten, T.E.L \& Molendijk, L.P.G. (2007) Field performance of Solanum sisymbriifolium, a trap crop for potato cyst nematodes. I. Dry matter accumulation in relation to sowing time, location, season and plant density. Annl Appl Biol150: 89-97.

Ubaidullah, Raziuddin, Mohammad, T., Hafeezullah and Ali, A. (2007) Characterization of wheat genotypes for yield and yield associated traits against terminal heat stress. Sarhad J Agric23: 94754.

Wahid, A., Gelani, S., Ashraf, M. and Foolad, M.R. (2007) Heat tolerance in plants: an overview. Environ Exp Bot61: 199-23.

\section{How to cite this article:}

Mavi. G. S., Harinderjeet Kaur, Parminder Kumar and Sohu. V. S. 2020. Criterion and Performance of Elite Bread Wheat Genotypes Pertaining to Physiological Traits under Abiotic Conditions. Int.J.Curr.Microbiol.App.Sci. 9(07): 173-188. doi: https://doi.org/10.20546/ijcmas.2020.907.021 